\title{
Fluid-mineral partitioning of REE in critical mineral deposits
}

\author{
ALEXANDER P. GYSI ${ }^{1,2}$ \\ ${ }^{1}$ Department of Geology and Geological Engineering, Colorado \\ School of Mines, Golden, CO 80401, USA, \\ ${ }^{2}$ New Mexico Bureau of Geology \& Mineral Resources, New \\ Mexico Institute of Mining and Technology, Socorro, NM \\ 87801, USA
}

Critical mineral deposits permit studying the cause of fractionation of rare earth elements (REE) in hydrothermal fluids, the stability of REE minerals, and also their partitioning behaviour as trace elements in vein minerals such as calcite, fluorite and apatite [1]. The behavior of the REE remains somewhat enigmatic. Despite their similar ionic radii and atomic properties, fluid-rock interaction processes can fractionate them in natural systems.

Significant advances have been made in our understanding and thermodynamic modeling of REE speciation in hydrothermal fluids [2]. However, studies on the solubility of simple REE mineral endmembers such as monazite $\left(\mathrm{CePO}_{4}\right)$ and xenotime $\left(\mathrm{YPO}_{4}\right)$ have shown that there are significant discrepancies between the thermodynamic data for minerals and certain REE aqueous species [3,4]. Furthermore, models for simulating trace element partitioning between hydrothermal fluids and minerals still need to be developed at temperatures above $100{ }^{\circ} \mathrm{C}$. Therefore, it is currently difficult to interpret field observations and the geochemistry of critical mineral deposits, and perhaps extend this knowledge to hydrothermal REE fractionation processes in other ore deposit types.

In this study, new experimental work is presented on the solubility of REE phosphates and REE fluid-mineral partition coefficients in calcite and apatite. These experimental data were implemented in the GEMS and GEMSFITS code packages $[5,6]$, which were used to develop new thermodynamic models. We show the potential for simulating the partitioning of REE between hydrothermal fluids and minerals, and showcase how such complex partitioning and solid solution models can be coupled into 1-D reactive transport models. We then discuss few case studies of REE partitioning in iron-oxide-apatite (IOA) and other REE deposits to compare the model with field observations.

[1] Perry and Gysi (2018), Geofluids 2018, 1-19; [2] Migdisov et al. (2016), Chem. Geol. 439, 13-42. [3] Gysi et al. (2015), Chem. Geol. 401, 83-95; [4] Gysi et al. (2018), Geochim. Cosmochim. Acta 242, 143-164; [5] Kulik et al. (2013), Computat. Geosci. 17, 1-24; [6] Miron et al. (2015), Appl. Geochem. 55, 28-45. 